\title{
Prevalence and predictors of overweight and obesity in Brazilian immigrants in Massachusetts
}

\author{
Rachel A. Klabunde ${ }^{1}$, Felippe Lazar Neto ${ }^{2}$, Andressa Louzada², Ricardo Faé de Moura ${ }^{3}$, Fernando Morelli Calixto ${ }^{3}$,
} Goodarz Danaei ${ }^{1,4}$ and Marcia C. Castro ${ }^{1 *}$ (i)

\begin{abstract}
Background: Overweight and obesity are important risk factors for chronic non-communicable diseases, and their prevalence is on the rise worldwide. This study seeks to describe the prevalence and predictors of overweight and obesity in Brazilian immigrants living in Massachusetts, United States of America (USA).

Methods: Modeled after a survey on behavioral risk factors for chronic disease conducted annually in Brazil (Vigilância de Fatores de Risco e Proteção para Doenças Crônicas por Inquérito Telefônico: Vigitel), Brazilian immigrants aged 18+ $(n=361)$ were surveyed between December 2013 and March 2014. Information was obtained from consenting participants regarding their demographic characteristics, physical activity, dietary and lifestyle habits, and other behavioral risk factors. Weight status was estimated from body mass index (BMI), calculated from selfreported height and weight data. Participants were categorized as overweight/obese if their BMI was $\geq 25$; overweight and obese categories were combined to ensure appropriate sample size. Prevalence of overweight/ obesity was estimated using STATA, and significant predictors were identified via multi-variable logistic regression. Odds ratio (OR), 95\% confidence intervals $(95 \% \mathrm{Cl})$ and $p$-values were determined.
\end{abstract}

Results: The overall prevalence of overweight/obesity in the sample was $47.6 \%$. Significant predictors of overweight and obesity were gender (men OR 2.30, 95\% Cl: 1.10, 3.78; women are comparison group), working in the 3 months prior to the survey (OR 2.90, 95\% Cl: 1.01, 8.30), and longer duration living in the USA (OR per additional year 1.06, $95 \%$ Cl: 1.02, 1.11). Significant dietary predictors of overweight/obesity included 5 or more days per week of consumption of red meat (OR red meat $3.70,95 \% \mathrm{Cl}$ : 1.47, 9.26) or of sweetened beverages, like soft drinks also known as soda (OR soda 2.40, 95\% Cl: 1.00, 5.78) compared with less frequent consumption of these foods.

Conclusions: This study suggests that long duration of time lived in the USA increases odds of overweight and obesity for Brazilian immigrants living in Massachusetts. Efforts to curb increases in overweight and obesity in this population should focus not only on the men and those who work but also the women. Possible intervention measures should target soda (soft drink) and red meat consumption in Brazilian immigrants.

Keywords: Immigrant health, Brazilians, USA, Overweight, Obesity, Consumption, Meat, Soda, Fruits, Vegetables

\footnotetext{
* Correspondence: mcastro@hsph.harvard.edu

${ }^{1}$ Harvard T.H. Chan School of Public Health, Department of Global Health \&

Population, 665 Huntington Avenue, Bldg. 1, Boston, MA 02215, USA

Full list of author information is available at the end of the article
}

(c) The Author(s). 2020 Open Access This article is distributed under the terms of the Creative Commons Attribution 4.0 International License (http://creativecommons.org/licenses/by/4.0/), which permits unrestricted use, distribution, and reproduction in any medium, provided you give appropriate credit to the original author(s) and the source, provide a link to the Creative Commons license, and indicate if changes were made. The Creative Commons Public Domain Dedication waiver (http://creativecommons.org/publicdomain/zero/1.0/) applies to the data made available in this article, unless otherwise stated. 


\section{Background}

The epidemic of overweight and obesity is at the forefront of global public health agendas. High body mass index (BMI) was ranked as the fifth-leading risk factor for death in 2016, globally [1]. In the USA, 39.8\% of adults aged 20 or older were obese in 2016 (BMI $\geq 30$ ) [2]. However, newly-arrived immigrants in the USA have lower levels of obesity, and better overall health, than the native-born population on arrival to the country [36]. This "healthy immigrant" phenomenon tends to fade over time. Immigrants who have lived in the USA for at least 15 years have overweight and obesity levels approaching those of USA-born adults [4, 7], and a positive association is generally found between duration of residence in the USA and BMI [4, 7-10]. Acculturation, or immigrant acceptance and adoption of behaviors and practices common in the host culture, is a common explanation for these findings $[8,11-14]$. Dietary acculturation, including increased consumption of fast food and soft drinks in the USA compared with the native country, is one potential mechanism for the observed relationship between time since immigration and increased weight $[10,15]$.

Much of the literature on immigrant health and acculturation in the USA has excluded an important group: Brazilian immigrants. The USA is home to the largest population of Brazilian immigrants in the world, and of the states, Massachusetts (MA) has the second-largest population of Brazilian immigrants after Florida [16]. According to estimates from the American Community Survey (ACS), 336,000 foreign-born Brazilians lived in the USA in 2014, with 61,000 of these living in MA [17]. However, these data could be significant underestimates, as approximately $70 \%$ of the Brazilian immigrant population in the USA are undocumented, making them less likely to be counted by surveys like the ACS [18]. Additionally, given the linguistic and cultural uniqueness of Brazilians among South Americans, they are less likely to be correctly counted in the U.S. Census (they are not considered to be "Hispanic", as Spanish is not their mother tongue) [18]. Few studies exist on the health status or risk factor profile of Brazilian immigrants in the USA $[16,18,19]$.

To fill this gap in the literature, this study seeks to estimate the prevalence of overweight and obesity in the Brazilian immigrant population living in MA, compare this prevalence with national estimates for the USA and Brazil, and identify predictors of overweight and obesity in this population.

\section{Methods}

\section{Participants and data collection}

To investigate the health status of Brazilian immigrants living in MA, a cross-sectional survey was conducted between December 2013 and March 2014. The survey was administered in person, with a convenience sample of 520 individuals in two settings. Sample size was determined based on researcher capacity at the time of survey. Most respondents (85\%) answered the survey while seeking services at the Consulate General of Brazil in Boston. The rest completed the survey following religious services for the Brazilian immigrant community at MA churches in Cambridge, Framingham, and Somerville, as these were known gathering places for the Brazilian immigrant community in the greater Boston area. The Consulate General of Brazil in Boston, MA was selected as the primary location for survey administration given the wide variety of services provided to Brazilians there (including issuing of documents, voting assistance, vital registration services, etc.), helping to ensure sampling of immigrants of varying age, socioeconomic status, place of residence within MA, and other demographic characteristics.

To be eligible to participate in the survey, a person had to be (a) born in Brazil; (b) 18 years old or older; and (c) living in MA at the time of survey. Informed consent was obtained from all individual participants included in the study. Consent was performed in Portuguese with the assistance of Brazilian medical students, and following consent, participants responded individually to the written questionnaire.

\section{Survey, health and lifestyle measures}

The survey was modelled after Vigitel (an annual, telephone risk factor surveillance survey used in Brazil: Vigilância de Fatores de Risco e Proteção para Doenças Crônicas por Inquérito Telefônico) [19]. While the original Vigitel survey has been used in Brazil since 2006 [19], the present survey was the first of its kind to survey chronic disease risk factors and to specifically sample Brazilians living in MA. It was designed to allow direct comparison with the Vigitel survey [19] in terms of risk and protective factors, with the addition of questions relevant to immigrants. Our survey also included time lived in the USA and in the current city of residence, English proficiency, changes in dietary patterns after immigrating, monthly income categories, as well as standardized questions to evaluate depression [20].

Height and weight were self-reported. Lifestyle habits assessed in the survey included physical activity, smoking habits, alcohol consumption, amount of time spent watching daily TV, and dietary habits. Specifically, respondents were asked about their frequency of consumption of a variety of foods (categorically, in days per week). Portion sizes of food consumption were not addressed in the survey. Respondents were also asked whether their consumption of these items and physical 
activity level had increased, decreased, or stayed the same compared with their habits when living in Brazil.

\section{Data analysis}

Self-reported height and weight were used to calculate BMI, and participants were classified as overweight/ obese if they had a BMI $\geq 25 \mathrm{~kg} / \mathrm{m} 2$ [21]. To be eligible for inclusion in this analysis, respondents must be Brazilian immigrants, have reported measures of height and weight, as well as all relevant covariates, selected based on a priori knowledge and relevant literature on overweight and obesity [22-25]. Pregnant women were excluded from the analysis. Varying degrees of missing data were present across these covariates. To examine whether missing data was associated with overweight and obesity, a "missing" category was created for all covariates with $>5 \%$ missing, and univariate logistic regression models of overweight and obesity on variables with missing data were run. Missing data was not statistically significantly associated with overweight and obesity; therefore, a complete case analysis of these data was performed (final sample $n=361$ ).

2Descriptive statistics of the sample were generated. Prevalence of overweight and obesity in the sample, as well as national prevalence estimates from the $2014 \mathrm{Na}$ tional Health Interview Survey (NHIS) [26] and the Brazil 2006-2015 Vigitel surveys [19] were age-standardized to the immigrant sample age distribution to allow for easy comparison. To assess predictors of overweight and obesity in this population, multivariable logistic regression of overweight/obese status on relevant covariates were run. Relevant covariates included in the model were selected based on a-priori knowledge of their relationship and were: gender; age (years); time living in the USA (years); marital status (currently married or not); education (completion of primary school, high school, college, graduate school); income (monthly income $\$ 600-\$ 1500$, $\$ 1500-\$ 3500$, >\$3500); work status (working in past 3 months); and frequency of consumption of red meat, soda (soft drink) or sweetened beverages, pizza and sandwiches, sweets, vegetables, and fruits (never/hardly ever, 1-4 days per week, 5+ days per week). Based on literature regarding overweight/obesity in Brazilians, interactions between gender and marriage, work, income, or education were tested via creation of interaction terms, which were included in the multivariable logistic model. Prior published analyses of depression in this sample have been published [20]; thus, depression status was not included in this analysis. All analyses were completed in STATA version 14.0 (Stata Corp.; College Station, TX, USA).

\section{Results}

Of the 520 initial participants in the survey, 8 pregnant women were excluded from the analysis, leaving 512 participants. An additional 151 participants were excluded due to missing data; 69 of these were missing height or weight information. The final sample eligible for this analysis included 361 Brazilian immigrants (170 men, 191 women) living in MA.

Sociodemographic characteristics for the final sample are presented in Table 1. Men made up slightly less than half of the sample (47.1\%). On average, participants had lived in the USA for 12.7 years, and respondents' average age was 39.5 years (ranging from 18 to 74 years). Approximately $45 \%$ of respondents had completed a university or graduate degree, and nearly $95 \%$ had worked in the 3 months prior to the survey. Almost half of the sample was overweight or obese $(47.6 \%)$. Dietary patterns of survey participants are presented in Table 2 . Normal weight and overweight or obese participants differed significantly in terms of gender and mean time living in the USA, as well as red meat and soda (soft drink) or sugary beverage consumption.

The overall prevalence of obesity in this sample was $47.6 \%$. When considered in different subgroups of the Brazilian immigrant population, however, prevalence varied. Among men in the sample, prevalence of overweight and obesity was $60.0 \%$, while just $36.7 \%$ of women were overweight and obese. Prevalence also differed by age group, as shown in Fig. 1, with the highest prevalence noted in the 55-64-year-old age group (70.0\%, women), and the lowest prevalence in the 3544-year-old age group (27.3\%, women). Agestandardized prevalence generally increased with 5-year increments living in the USA. However, this relationship differed between men and women (see Fig. 2). For men, age-standardized prevalence was low (23.4\%) in those living in the USA for 0-4 years and then increased dramatically with each 5 more years of living in the USA. In contrast, the lowest prevalence of overweight and obesity in women was in those living in the USA 5-9years (19.5\%), with a peak in those having lived in the USA for 15-19 years. Of note, age-adjusted estimates stratified by gender and time spent in the USA contained sparse strata, with corresponding increases in uncertainty.

Comparisons of age-adjusted prevalence of overweight and obesity in the sample with national levels for the USA (from the 2014 NHIS) and Brazil (from the 2014 Vigitel) revealed that the immigrant population had a lower prevalence of overweight and obesity than either of the national estimates. Urban Brazil's prevalence of overweight and obesity was $54.4 \%$, and the USA had a prevalence of $62.0 \%$ in 2014 (compared with the Brazilian immigrant sample's $47.6 \%$ prevalence). Additionally, when considering the series of available Vigitel data (annually conducted since 2006), Brazilian immigrants living in MA had an ageadjusted prevalence of overweight and obesity most closely resembling urban Brazil in 2008 (see Fig. 3). 
Table 1 Socio-demographic characteristics of Brazilian immigrant sample, 2014

\begin{tabular}{|c|c|c|c|c|}
\hline Characteristic & $\begin{array}{l}\text { Total Sample } \mathrm{N} \\
\text { (\% of total) }\end{array}$ & $\begin{array}{l}\text { Under/Normal Weight } \\
\left(\text { BMI }{ }^{\mathrm{b}}<25\right) \mathrm{N}(\% \text { of column) }\end{array}$ & $\begin{array}{l}\text { Overweight or Obese }{ }^{d} \\
(B M I \geq 25) \mathrm{N} \text { (\% of column) }\end{array}$ & $P$-Value \\
\hline Overweight or Obese & $172(47.6)$ & - & - & - \\
\hline \multicolumn{5}{|l|}{ Gender } \\
\hline Men & $170(47.1)$ & $68(36.0)$ & $102(59.3)$ & $<0.001$ \\
\hline Women & $191(52.9)$ & $121(64.0)$ & $70(40.7)$ & $<0.001$ \\
\hline Mean Age, years & 39.5 & 38.7 & 40.3 & 0.143 \\
\hline Mean Years Living in USA (SD) & $12.7(6.7)$ & $11.6(6.2)$ & $13.9(7.1)$ & 0.001 \\
\hline Currently Married & $208(57.6)$ & $107(56.6)$ & $101(58.7)$ & 0.686 \\
\hline \multicolumn{5}{|l|}{ Education } \\
\hline Primary School & $61(16.9)$ & $25(13.2)$ & $36(20.9)$ & 0.051 \\
\hline High School & $137(38.0)$ & $72(38.1)$ & $65(37.8)$ & 0.953 \\
\hline University Degree & $122(33.8)$ & $65(34.4)$ & $57(33.1)$ & 0.802 \\
\hline Graduate Degree & $41(11.4)$ & $27(14.3)$ & $14(8.1)$ & 0.067 \\
\hline Worked in Past 3 Months & $341(94.5)$ & $181(95.8)$ & $160(93.0)$ & 0.256 \\
\hline \multicolumn{5}{|l|}{ Monthly Income } \\
\hline$\$ 600-\$ 1500$ & $103(28.5)$ & $54(28.6)$ & $49(28.5)$ & 0.310 \\
\hline$\$ 1500-\$ 3500$ & $162(44.9)$ & $89(47.1)$ & $73(42.4)$ & 0.375 \\
\hline$>\$ 3500$ & 96 (26.6) & $46(24.3)$ & $50(29.1)$ & 0.986 \\
\hline
\end{tabular}

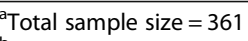

${ }^{\mathrm{b}}$ Under/normal weight sample $=189$

${ }^{c} B M I$ Body mass index



Results of a multivariable adjusted logistic regression identified significant predictors of overweight and obesity in this population (see Table 3 ). Men had 2.30 times the odds of overweight and obesity compared with women (OR 2.30, 95\% CI: 1.10, 3.78). Each additional year of living in the USA added $6 \%$ to the odds of overweight and obesity in the sample $(\mathrm{OR}=1.06,95 \% \mathrm{CI}$ : $1.02,1.11)$. Those who had worked in the 3 months prior to the survey had 2.9 times the odds of overweight and obesity compared with those who had not worked (OR = 2.90, 95\% CI: 1.01, 8.30). Marital status, education, and income made no significant difference in the odds of overweight and obesity in this population.

Frequent consumption of red meat was a strong predictor of overweight and obesity. Those who typically consumed 5 or more servings of red meat per week had 3.7 times the odds of overweight and obesity than those who never consume red meat $(\mathrm{OR}=3.70,95 \%$ CI: 1.47 , 9.26). Regular consumption of soda (soft drink) or other sugar-sweetened drinks was also harmful, as 5 or more servings of soda (soft drink) per week was associated with 2.4 times the odds of overweight and obesity $(\mathrm{OR}=$ $2.40,95 \%$ CI: 1.00, 5.78). Other dietary factors were not significantly associated with overweight and obesity.

No significant interactions were detected between gender and marital status, work status in the past 3 months or education.

\section{Discussion}

This analysis describes the prevalence of overweight or obesity in the Brazilian immigrant population living in MA, demonstrating that this population has lower ageadjusted prevalence than national estimates for both its native and immigration destination countries. Brazilians living in MA most closely resemble urban Brazilians from 2008 in terms of age-adjusted overweight and obesity prevalence. Duration of residence in the USA is a significant predictor of overweight and obesity, with odds of overweight and obesity increasing $6 \%$ with each additional year of residence after controlling for age and other relevant covariates. Men and those who have worked in the past 3 months have greater odds of overweight and obesity than women or those who have not worked in the past 3 months. Finally, frequent consumption of red meat and soda (soft drink) or other sugary beverages are associated with higher odds of overweight and obesity.

Findings of increasing prevalence and odds of overweight and obesity with greater duration of residence in the USA is consistent with the current literature on immigrant overweight and obesity in this country, for Latinos as well as other immigrant groups [12, 27]. The lower prevalence of overweight and obesity in the Brazilian immigrant population than national estimates for both Brazil and the USA coincides with the well- 
Table 2 Dietary characteristics of Brazilian immigrant sample, 2014

\begin{tabular}{|c|c|c|c|c|}
\hline Food / Frequency of Consumption & $\begin{array}{l}\text { Total Sample } e^{a} N \\
\text { (\% of total) }\end{array}$ & $\begin{array}{l}\text { Under/Normal Weight } \\
\left(\text { BMI }^{\mathrm{c}}<25\right) \mathrm{N}(\% \text { of column) }\end{array}$ & $\begin{array}{l}\text { Overweight or Obese } \\
(B M I \geq 25) N(\% \text { of column) }\end{array}$ & $P$-Value \\
\hline \multicolumn{5}{|l|}{ Red Meat } \\
\hline Never-Hardly Ever & $50(13.9)$ & $32(16.9)$ & $18(10.5)$ & 0.076 \\
\hline 1-4 Days per Week & $242(67.0)$ & $133(70.4)$ & $109(63.4)$ & 0.158 \\
\hline 5 Days per Week- Everyday & $69(19.1)$ & $24(12.7)$ & $45(26.2)$ & 0.001 \\
\hline \multicolumn{5}{|l|}{ Pizza and Sandwich } \\
\hline Never-Hardly Ever & $167(46.2)$ & $81(42.9)$ & $86(50.00)$ & 0.174 \\
\hline 1-4 Days per Week & $180(49.9)$ & $101(53.4)$ & $79(45.9)$ & 0.154 \\
\hline 5 Days per Week-Everyday & $14(3.9)$ & $7(3.7)$ & $7(4.1)$ & 0.857 \\
\hline \multicolumn{5}{|l|}{ Sweets (Cookies, Cakes, Candy, etc.) } \\
\hline Never-Hardly Ever & $101(28.0)$ & $56(29.6)$ & $45(26.2)$ & 0.464 \\
\hline 1-4 Days per Week & $189(52.4)$ & $90(47.6)$ & $99(57.6)$ & 0.059 \\
\hline 5 Days per Week-Everyday & $71(19.7)$ & $43(22.8)$ & $28(16.3)$ & 0.122 \\
\hline \multicolumn{5}{|l|}{ Soda'/Sugary Beverage } \\
\hline Never-Hardly Ever & $195(54.0)$ & $115(60.9)$ & $80(46.5)$ & 0.006 \\
\hline 1-4 Days per Week & $128(35.5)$ & $59(31.2)$ & $69(40.1)$ & 0.078 \\
\hline 5 Days per Week-Everyday & $38(10.5)$ & $15(7.9)$ & $23(13.4)$ & 0.093 \\
\hline \multicolumn{5}{|l|}{ Fruit } \\
\hline Never-Hardly Ever & $26(7.2)$ & $10(5.3)$ & $16(9.3)$ & 0.141 \\
\hline 1-4 Days per Week & $187(51.8)$ & $98(51.9)$ & $89(51.7)$ & 0.984 \\
\hline 5 Days per Week-Everyday & $148(41.0)$ & $81(42.9)$ & $67(39.0)$ & 0.451 \\
\hline \multicolumn{5}{|l|}{ Vegetable } \\
\hline Never-Hardly Ever & $6(1.7)$ & $2(1.1)$ & $4(2.3)$ & 0.347 \\
\hline 1-4 Days per Week & $134(37.1)$ & $69(36.5)$ & $65(37.8)$ & 0.801 \\
\hline 5 Days per Week-Everyday & $221(61.2)$ & $118(62.4)$ & $103(59.9)$ & 0.619 \\
\hline
\end{tabular}

${ }^{\mathrm{a}}$ Total sample size $=361$

${ }^{\mathrm{b}}$ Under/Normal weight sample $=189$

${ }^{c} B M I$ Body mass index

${ }^{\mathrm{d} O v e r w e i g h t}$ or obese sample $=172$

eSoda refers to soft drinks

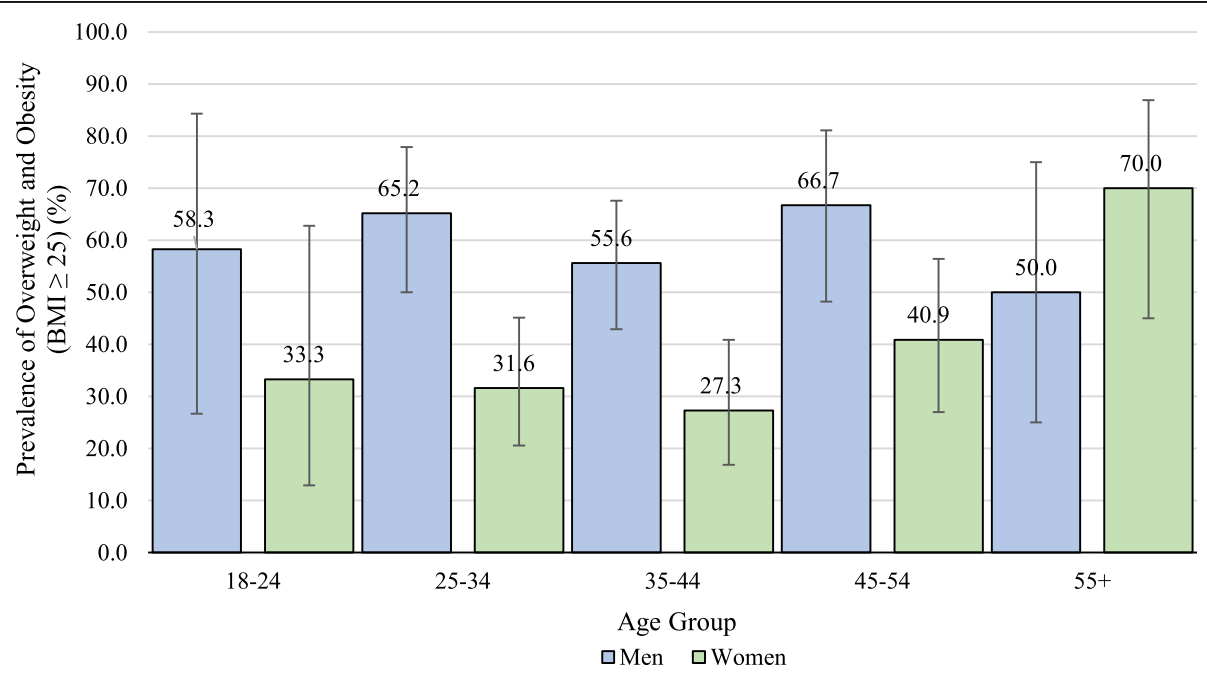

Fig. 1 Prevalence of overweight and obesity by age group and gender in Brazilian immigrant sample, 2014. Legend: Bars represent 95\% confidence intervals; $\mathrm{BMI}=$ body mass index 


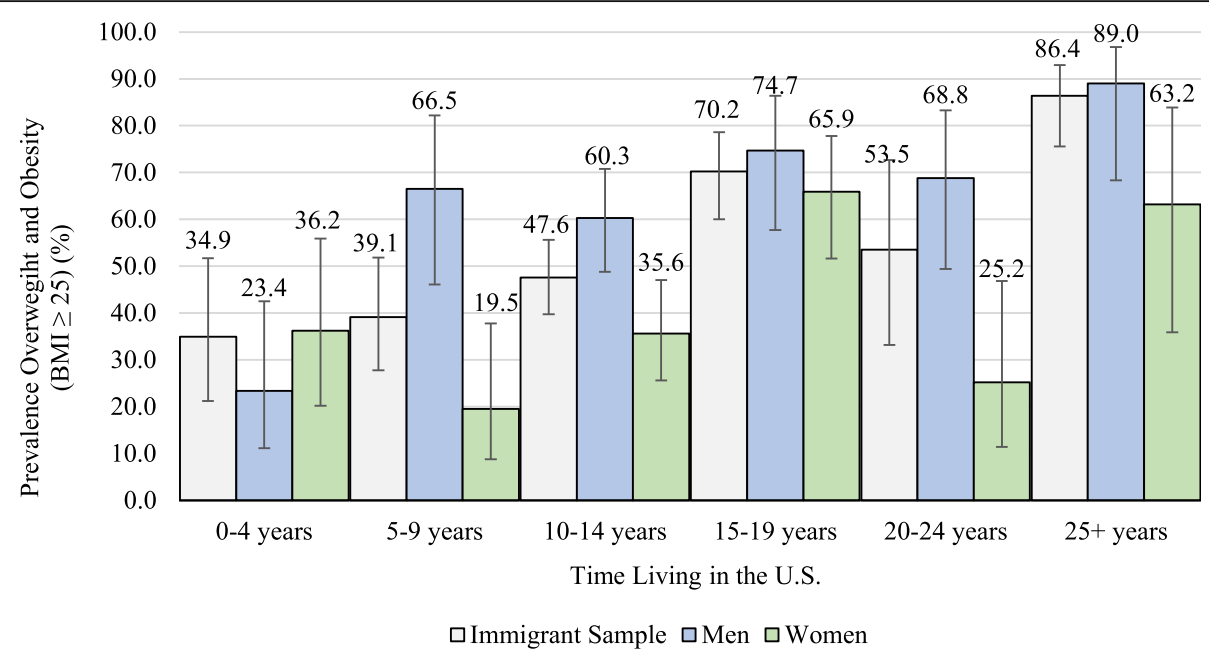

Fig. 2 Age-standardized prevalence of overweight and obesity by time lived in the USA and gender in Brazilian immigrant sample, 2014. Legend: prevalence age-standardized to immigrant population age distribution; bars represent $95 \%$ confidence intervals; $\mathrm{BMI}=$ body mass index

described "healthy immigrant" phenomenon. The consensus, however, is that the health advantage immigrants possess fades over time, with weight gain and increased rates of overweight and obesity observed in immigrants who have lived in the USA for longer periods $[4,5,28]$; findings from this study are in agreement with this consensus.

Another explanation for the increase in overweight and obesity and general worsening of health observed in immigrant populations of all countries of origin is acculturation, or unhealthy assimilation, to poor dietary patterns common in the USA [4, 6, 27]. Data on dietary changes since moving to the USA were not included in this analysis, due to frequent missing data $(>20 \%$ for some foods) and concerns about recall bias, given the long mean duration of living in the USA (12.7 years). However, a greater number of survey participants included in this analysis responded to a question regarding physical activity change, with more than half of participants $(n=194,53.7 \%)$ reporting they perform less physical activity in the USA than when they lived in Brazil. Unhealthy assimilation of health behaviors may be one explanation for increased odds of overweight and obesity with each year lived in the USA. Dietary predictors of overweight and obesity in this population include frequent ( $\geq 5$ servings per week) consumption of red meat

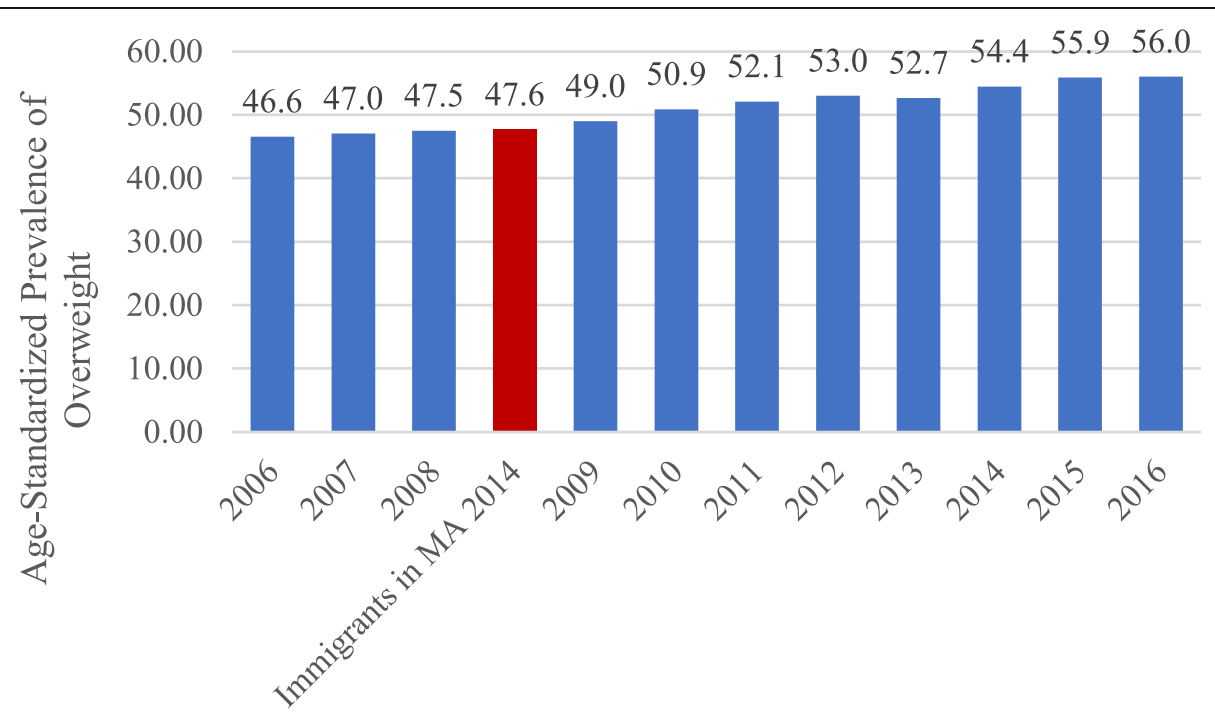

Fig. 3 Age-standardized prevalence of overweight and obesity from Brazilian immigrant sample and Vigitel series from urban Brazil (age 18-65+), 2006-2016. Legend: prevalence age-standardized to immigrant population age distribution, immigrant sample prevalence shown in red; BMI= body mass inde 
Table 3 Multi-variable logistic regression of overweight and obesity on selected covariates

\begin{tabular}{|c|c|c|c|}
\hline Covariate & OR & $P$-Value & $95 \% \mathrm{Cl}$ \\
\hline \multicolumn{4}{|l|}{ Gender } \\
\hline Women & Ref & - & - \\
\hline Men & 2.30 & 0.001 & $(1.40-3.78)$ \\
\hline Age & 1.00 & 0.771 & $(0.98-1.03)$ \\
\hline Time Living in the USA & 1.06 & 0.005 & $(1.02-1.11)$ \\
\hline Currently Married & 1.05 & 0.848 & $(0.64-1.71)$ \\
\hline \multicolumn{4}{|l|}{ Education } \\
\hline Primary School & Ref & - & - \\
\hline High School & 0.64 & 0.188 & $(0.33-1.24)$ \\
\hline University Degree & 0.91 & 0.795 & $(0.44-1.86)$ \\
\hline Graduate Degree & 0.46 & 0.105 & $(0.18-1.18)$ \\
\hline Worked in Past 3 Months & 2.90 & 0.047 & $(1.01-8.30)$ \\
\hline \multicolumn{4}{|l|}{ Monthly Income } \\
\hline$\$ 600-\$ 1500$ & Ref & - & - \\
\hline$\$ 1500-\$ 3500$ & 0.95 & 0.867 & $(0.54-1.67)$ \\
\hline$>s \$ 3500$ & 1.03 & 0.932 & $(0.53-2.00)$ \\
\hline \multicolumn{4}{|l|}{ Red Meat Consumption } \\
\hline Never-Hardly Ever & Ref & - & - \\
\hline 1-4 Days per Week & 1.67 & 0.165 & $(0.87-3.49)$ \\
\hline 5 Days per Week-Everyday & 3.70 & 0.005 & $(1.47-9.25)$ \\
\hline \multicolumn{4}{|c|}{ Pizza and Sandwich Consumption } \\
\hline Never-Hardly Ever & Ref & - & - \\
\hline 1-4 Days per Week & 0.49 & 0.012 & $(0.28-0.86)$ \\
\hline 5 Days per Week-Everyday & 0.59 & 0.444 & $(0.15-2.29)$ \\
\hline \multicolumn{4}{|c|}{ Sweets (Cookies, Cakes, Candy, etc.) } \\
\hline Never-Hardly Ever & Ref & - & - \\
\hline 1-4 Days per Week & 1.55 & 0.125 & $(0.88-2.73)$ \\
\hline 5 Days per Week-Everyday & 0.96 & 0.916 & $(0.44-2.05)$ \\
\hline \multicolumn{4}{|c|}{ Soda/Sugary Beverage Consumption } \\
\hline Never-Hardly Ever & Ref & - & - \\
\hline 1-4 Days per Week & 1.60 & 0.109 & $(0.90-2.85)$ \\
\hline 5 Days per Week-Everyday & 2.40 & 0.050 & $(1.00-5.78)$ \\
\hline \multicolumn{4}{|l|}{ Fruit Consumption } \\
\hline Never-Hardly Ever & Ref & - & - \\
\hline 1-4 Days per Week & 0.50 & 0.160 & $(0.19-1.32)$ \\
\hline 5 Days per Week-Everyday & 0.50 & 0.170 & $(0.18-1.35)$ \\
\hline \multicolumn{4}{|l|}{ Vegetable Consumption } \\
\hline Never-Hardly Ever & Ref & - & - \\
\hline 1-4 Days per Week & 0.38 & 0.334 & $(0.05-2.68)$ \\
\hline 5 Days per Week-Everyday & 0.45 & 0.425 & $(0.06-3.17)$ \\
\hline
\end{tabular}

and sweetened beverages; frequent consumption of sweetened beverages has been positively correlated with overweight in immigrant and other populations in the USA [10]. Challenges immigrants face with regards to legal immigration status, employment, income generation, food and housing security, and other social determinants of health may also contribute to overweight and obesity status with time lived in the USA, though these are outside the scope of the present study or analysis.

There were some important limitations to consider with the results of this analysis. First, all data analyzed were self-reported. Particularly with self-reported weight and height, there is evidence that weight tends to be underestimated relative to measured weight (especially by women), with the opposite being true for height (especially by men) $[29,30]$, resulting in underestimation of BMI. This is an important consideration for the prevalence of overweight and obesity in this immigrant population. However, this should not affect the prevalence comparisons in this analysis, as Vigitel data from Brazil and the NHIS from the USA also used self-reported height and weight.

Next, it is important to note that the survey was administered with convenience sampling, and thus these results may not be generalizable to all Brazilians living in MA. Sampling the majority of immigrants at the Consulate General in Boston sought to obtain a more representative sample than religious gatherings, given the wide range of services provided at the Consulate, but representativeness of the statewide population of Brazilian immigrants cannot be guaranteed. Nevertheless, a comparison of the demographics of Brazilian immigrants living in MA from the 2014 ACS (a random sample survey conducted through the U.S. Census Bureau) with those in this survey suggests that our sample does not differ significantly from this population in terms of age, gender, English proficiency, or time living in the USA [31]. Our sample did include a higher proportion of individuals who were apparently healthy, currently married, currently employed, or had completed a graduate degree than the Brazilian-born population in the 2014 ACS. Particularities of MA as a state (such as high levels of insurance coverage) [32] may make this sample not representative of Brazilian immigrants nationally. While physical activity levels are a recognized determinant of overweight and obesity, measures of physical activity were not included in this analysis due to significant inconsistency in reporting in terms of activity frequency. Finally, the complete case analysis approach could lead to biased estimates if missing data were not missing at random. Our results indicated that missing covariate data were not associated with the main outcome of interest.

This analysis presents novel estimates of the prevalence of overweight/obesity and associated predictors in 
Brazilian immigrants living in MA. The positive finding that this population has a lower prevalence of overweight and obesity than its native counterparts in the USA or Brazil supports the "healthy immigrant" phenomenon observed in other literature [3-5]. Given the increasing odds of overweight and obesity in this population with duration of stay in the USA, targeted efforts should be made with this population to avoid unhealthy assimilation to USA culture. Particularly, the population should be encouraged to decrease red meat and soda (soft drink) consumption, and men and those who work should be of particular focus in these efforts.

Dissemination of these messages could potentially be spearheaded through the Consulate General of Brazil in Boston, MA or the religious communities used for sampling for this study; churches have been found to be effective settings for delivery of evidence-based obesity treatment interventions for Latino adults in the USA [33]. Other local organizations that work with immigrant communities, and Brazilians in particular, could be particularly useful hosts for intervention. The Brazilian Immigration Center/Brazilian Worker Center, the Massachusetts Alliance of Portuguese Speakers, and the Brazilian Women's Group all have regular gatherings and offices throughout the state that provide health, employment, legal, immigration, and other services to the Brazilian immigrant population. A systematic review of obesity prevention intervention studies for immigrants found that interventions that had positive effects for obesity had a cultural focus, incorporated a participatory approach, and engaged the community via implementation in existing community structures, like those in MA [34]. Local Brazilian radio stations found around the state (Radio Brazuca, WSRO Framingham/Boston, or Transameria Hitz Boston) could promote these community-based interventions. Interventions targeted to this population should be led by community members who are fluent in Portuguese; engaging those of Brazilian descent could increase engagement of immigrants in the interventions and potentially increase their effectiveness [33]. Finally, the literature on obesity prevention and treatment interventions for Brazilian immigrants (and immigrants in general) is relatively scarce. There is an increasing number of immigrants in the USA, including the Brazilian immigrant population, who play an important role in the state of MA. Identifying additional effective, evidence-based health interventions in this population should be a priority for future research.

\footnotetext{
Abbreviations

ACS: American Community Survey; BMI: Body Mass Index; Cl: Confidence Intervals; MA: Massachusetts; NHIS: National Health Interview Survey; OR: Odds Ratio; USA: United States of America; Vigitel: Vigilância de Fatores de Risco e Proteção para Doenças Crônicas por Inquérito Telefônico
}

Acknowledgements

Not applicable.

\section{Authors' contributions}

RAK contributed to the design, data analysis, and interpretation and writing of first and subsequent drafts of the paper. FLN, AL, RFdM, and FMC contributed to the research design and data collection. GD contributed to data analysis, interpretation, and editing the paper. MCC contributed to the design, data analysis, interpretation, and drafts of the paper. All authors read and approved the final manuscript.

\section{Funding}

Funding was not obtained for the completion of this study.

\section{Availability of data and materials}

The datasets used and/or analyzed during the current study are available from the corresponding author on reasonable request.

Ethics approval and consent to participate

All procedures performed in studies involving human participants were in accordance with the ethical standards of the institutional and/or national research committee and with the 1964 Helsinki declaration and its later amendments or comparable ethical standards. Ethical approval for this study was granted by the Harvard T. H. Chan School of Public Health Institutional Review Board (Protocol \#13-2450). Written informed consent was obtained from all individual participants included in the study.

Consent for publication

Not applicable.

\section{Competing interests}

The authors declare that they have no competing interests.

\section{Author details}

${ }^{1}$ Harvard T.H. Chan School of Public Health, Department of Global Health \& Population, 665 Huntington Avenue, Bldg. 1, Boston, MA 02215, USA.

${ }^{2}$ Faculty of Medical Sciences, University of São Paulo, São Paulo, Brazil. ${ }^{3}$ Santa Casa of São Paulo, Faculty of Medical Sciences, São Paulo, Brazil. ${ }^{4}$ Harvard T.H. Chan School of Public Health, Department of Epidemiology, Boston, MA, USA.

Received: 3 April 2019 Accepted: 31 December 2019

Published online: 10 January 2020

\section{References}

1. Gakidou E, Afshin A, Abajobir AA, Abate KH, Abbafati C, Abbas KM, et al. Global, regional, and national comparative risk assessment of 84 behavioural, environmental and occupational, and metabolic risks or clusters of risks, 1990-2016: a systematic analysis for the global burden of disease study 2016. Lancet. 2017;390:1345-422.

2. Hales CM, Carroll MD, Fryar CD, Ogden CL. Prevalence of obesity among adults and youth: United States, 2015-2016. In: Statistics NCfH: National Center for Health Statistics; 2017. https:/www.cdc.gov/nchs/data/databriefs/db288.pdf.

3. Corlin L, Woodin M, Thanikachalam M, Lowe L, Brugge D. Evidence for the healthy immigrant effect in older Chinese immigrants: a cross-sectional study. BMC Public Health. 2014;14:603.

4. Delavari M, Sønderlund AL, Swinburn B, Mellor D, Renzaho A. Acculturation and obesity among migrant populations in high income countries - a systematic review. BMC Public Health. 2013;13:458.

5. Kennedy S, McDonald JT, Biddle N. The healthy immigrant effect and immigrant selection: evidence from four countries, Citeseer. Social and Economic Dimensions of an Aging Population Research Papers 164. McMaster University 2006. https://ideas.repec.org/p/mcm/sedapp/164.html.

6. Park J, Myers D, Kao D, Min S. Immigrant obesity and unhealthy assimilation: alternative estimates of convergence or divergence, 1995-2005. Soc Sci Med. 2009:69:1625-33.

7. Goel MS, McCarthy EP, Phillips RS, Wee CC. Obesity among U.S. immigrant subgroups by duration of residence. JAMA. 2004;292(23):2860-7.

8. Creighton MJ, Goldman N, Pebley AR, Chung CY. Durational and generational differences in Mexican immigrant obesity: is acculturation the explanation? Soc Sci Med. 2012;75(2):300-10.

9. Cho Y, Frisbie WP, Hummer RA, Rogers RG. Nativity, duration of residence, and the health of Hispanic adults in the United States. Int Migr Rev. 2004; 38(1):184-211. 
10. Oza-Frank R, Cunningham SA. The weight of US residence among immigrants: a systematic review. Obes Rev. 2010;11(4):271-80.

11. Buscemi J, Beech B, Relyea G. Predictors of obesity in Latino children: acculturation as a moderator of the relationship between food insecurity and body mass index percentile. J Immigr Minor Health. 2011;13(1):149-54.

12. Lara M, Gamboa C, Kahramanian MI, Morales LS, Bautista DEH. Acculturation and Latino health in the United States: a review of the literature and its sociopolitical context. Annu Rev Public Health. 2005;26:367.

13. Thomson MD, Hoffman-Goetz L. Defining and measuring acculturation: a systematic review of public health studies with Hispanic populations in the United States. Soc Sci Med. 2009:69(7):983-91.

14. Zambrana RE, Carter-Pokras O. Role of acculturation research in advancing science and practice in reducing health care disparities among Latinos. Am J Public Health. 2010;100(1):18-23.

15. Roshania R, Narayan K, Oza-Frank R. Age at arrival and risk of obesity among US immigrants. Obesity. 2008;16(12):2669-75.

16. Zong J, Batalova J. Brazilian immigrants in the United States. 2016. Available from: http://www.migrationpolicy.org/article/brazilian-immigrants-unitedstates. Accessed 20 Jan 2017.

17. U.S. immigrant population by state and county [Internet]. 2016. Available from: http://www.migrationpolicy.org/programs/data-hub/charts/usimmigrant-population-state-and-county? width $=1000 \&$ height=850\&iframe $=$ true. Accessed 22 Jan 2017

18. Skidmore T: Brazilians in the U.S. Brown University Library. 2010. Available from: https://library.brown.edu/create/fivecenturiesofchange/chapters/ chapter-9/brazilians-in-the-u-s/. Accessed 15 Jan 2017.

19. Brasil, Ministry of Health. Vigitel Brazil 2006-2016: surveillance of risk and protective factors for chronic diseases by telephone survey: estimates of sociodemographic frequency and distribution of risk and protective factors for chronic diseases in the capitals of the 26 Brazilian states and the Federal District in 2006-2016. Brasília: Ministério da Saúde; 2017. p. 17.

20. Lazar-Neto F, Louzada ACS, de Moura RF, Calixto FM, Castro MC. Depression and its correlates among Brazilian immigrants in Massachusetts, USA. J Immigr Minor Health. 2018;20(4):832-40.

21. WHO. Obesity and overweight. 2016. Available from: http://www.who.int/ mediacentre/factsheets/fs311/en/. Accessed 15 Jan 2017.

22. Gigante D, de Moura EC, Sardinha L. Prevalence of overweight and obesity and associated factors, Brazil, 2006. Rev Saude Publica. 2009:43:83-9.

23. Gigante DP, GVAd F, LMV S, BPM I, Meléndez GV. Variação temporal na prevalência do excesso de peso e obesidade em adultos: Brasil, 2006 a 2009. Revista Brasileira de Epidemiologia. 2011;14(suppl 1):157-65.

24. VSd S, Petroski EL, Souza I, DAS S. Prevalência e fatores associados ao excesso de peso em adultos do Brasil: um estudo de base populacional em todo território nacional. Revista Brasileira de Ciências Esporte. 2012;34:713-26.

25. Steele EM, Claro RM, Monteiro CA. Behavioural patterns of protective and risk factors for non-communicable diseases in Brazil. Public Health Nutr. 2014;17(2):369-75.

26. CDC. National health interview survey: table A-15: body mass index among adults aged 18 and over, by selected characteristics: United States, 2014. In: Statistics NCFH; 2015.

27. Antecol H, Bedard K. Unhealthy assimilation: why do immigrants converge to American health status levels? Demography. 2006;43(2):337-60.

28. Akresh $I R$. Dietary assimilation and health among Hispanic immigrants to the United States. J Health Soc Behav. 2007:48(4):404-17.

29. Gorber SC, Tremblay M, Moher D, Gorber B. A comparison of direct vs. selfreport measures for assessing height, weight and body mass index: a systematic review. Obes Rev. 2007;8(4):307-26.

30. Ezzati M, Martin H, Skjold S, Vander Hoorn S, Murray C. Trends in national and state-level obesity in the USA after correction for self-report bias: analysis of health surveys. J R Soc Med. 2006:99(5):250-7.

31. American community survey [Internet]. 2014. Available from: https://wuw.census. gov/acs/www/data/data-tables-and-tools/index.php. Accessed 10 Jan 2017.

32. Doonan MT, Tull KR. Health care reform in Massachusetts: implementation of coverage expansions and a health insurance mandate. Milbank Q. 2010;88(1):54-80.

33. Perez LG, Arredondo EM, Elder JP, Barquera S, Nagle B, Holub CK. Evidencebased obesity treatment interventions for Latino adults in the U.S.: a systematic review. Am J Prev Med. 2013;44(5):550-60.

34. Tovar A, Renzaho AMN, Guerrero AD, Mena N, Ayala GX. A systematic review of obesity prevention intervention studies among immigrant populations in the US. Curr Obes Rep. 2014;3(2):206-22.

\section{Publisher's Note}

Springer Nature remains neutral with regard to jurisdictional claims in published maps and institutional affiliations.
Ready to submit your research? Choose BMC and benefit from:

- fast, convenient online submission

- thorough peer review by experienced researchers in your field

- rapid publication on acceptance

- support for research data, including large and complex data types

- gold Open Access which fosters wider collaboration and increased citations

- maximum visibility for your research: over $100 \mathrm{M}$ website views per year

At BMC, research is always in progress.

Learn more biomedcentral.com/submissions 